\title{
On the assimilation of total-ozone satellite data
}

\author{
P. F. Levelt, M. A. F. Allaart, H. M. Kelder \\ Royal Netherlands Meteorological Institute (KNMI), 3730 AE De Bilt, The Netherlands \\ Received: 2 November 1995/Revised: April 1996/Accepted: 3 April 1996
}

\begin{abstract}
A two-dimensional model for advection and data assimilation of total-ozone data has been developed. The Assimilation Model KNMI (AMK) is a global model describing the transport of the column amounts of ozone, by a wind field at a single pressure level, assuming that total ozone behaves as a passive tracer. In this study, ozone column amounts measured by the TIROS Operational Vertical Sounder (TOVS) instrument on the National Oceanic and Atmospheric Administration (NOAA) polar satellites and wind fields from the Meteorological Archive and Retrieval System (MARS) archives at ECMWF have been used. By means of the AMK, the incomplete space-time distribution of the TOVS measurements is filled in and global total-ozone maps at any given time can be obtained. The choice of wind field to be used for transporting column amounts of ozone is extensively discussed. It is shown that the $200-\mathrm{hPa}$ wind field is the optimal single-pressure-level wind field for advecting total ozone. Assimilated ozone fields are the basic information for research on atmospheric chemistry and dynamics, but are also important for the validation of ozone measurements.
\end{abstract}

\section{Introduction}

Satellite measurements and ground-based measurements of ozone are essential for understanding the dynamical and chemical behaviour of ozone, for studying the ozonehole phenomena, for detecting trends in the ozone distribution and for determining the climatology of ozone. Global coverage of satellite measurements is important for most of these studies mentioned. Global total-ozone measurements are produced by satellite instruments like the Total Ozone Monitoring Spectrometer (TOMS) (Stolarski et al., 1991), the Solar Backscatter Ultraviolet

Correspondence to: P. F. Levelt
Radiometer (SBUV) (Heath et al., 1975), the TIROS Operational Vertical Sounder (TOVS) (Planet et al., 1984), the Global Ozone Monitoring Experiment (GOME) (Hahne et al., 1993) and, in the near future, the Scanning Imaging Absorption Spectrometer for Atmospheric Cartography (SCIAMACHY) on board of ENVISAT (ESA's, European Space Agency, Environmental Satellite) and the Ozone Monitoring Instrument (OMI) (ESA document, in preparation, 1996) on board of METOP (EUMETSAT's, European Organization for the Exploration of Meteorological Satellites, Meteorological Operational Program). The GOME instrument on board of the ERS-2 satellite, ESA's Earth Resource Satellites, was launched in April 1995. GOME measures ozone and other trace gases and has a swath width of $960 \mathrm{~km}$. This will result a global coverage in three days.

For several of the mentioned studies, monitoring of the distribution of ozone is needed on a daily basis. However, the ozone maps are often hampered by missing data due to, for example, retrieval problems in the case of clouds (TOVS) or limited swath width (SBUV, GOME). In these cases only sparse data are obtained, and it is often difficult to characterise features in the ozone distribution. The atmospheric circulation and the total-ozone content of the atmosphere are strongly correlated. This has already been recognised for the northern hemisphere for almost seventy years (Dobson et al., 1928 and Dobson, 1968). In general, a high-pressure region will give rise to low ozone values, while an extratropical low will show up as a region with high gradients in total-ozone values and high total-ozone values behind the centre of the low (Heijboer et al., 1996). This relation can be quantified using the correlation between vertically integrated potential vorticity and total ozone, as found by Allaart et al. (1993). In Fig. 1a, a map of retrieved TOVS satellite data measured on 23 April 1992 is shown. The data have been gathered over a period of $24 \mathrm{~h}$. Due to missing data (normally only one-third of the globe is covered with TOVS data), it is difficult to recognise specific features or coherent structures in the global ozone field. Another fundamental problem with the use of data from polar orbiting satellites is that the observations 


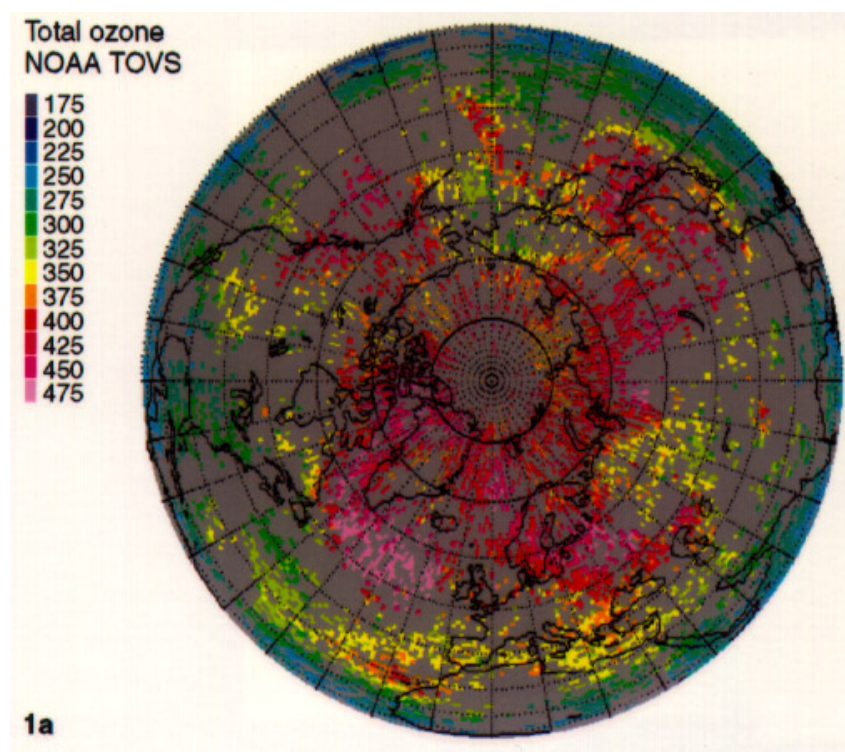

Fig. 1. a Raw NOAA TOVS total-ozone data (in DU) for 23 April 1992; b assimilated NOAA TOVS total-ozone data (in DU) for 23 April 1992 at 1200 UTC

are not made simultaneously. Global maps can be constructed by overlaying subsequent tracks observed at different times. However, spurious gradients due to changes in the ozone distribution in time can occur between adjacent tracks measured at different times. An example of this is shown in Fig. 2, where the global ozone map of 23 April 1992 produced from Nimbus-7 TOMS-data constructed by overlaying subsequent tracks is presented. Spurious gradients on the dateline at $180^{\circ} \mathrm{E}$, at the top of the picture, are clearly visible.

Data-assimilation techniques can be used to perform a more sophisticated interpolation. By taking into account the transport of ozone, maps of the total-ozone distribution at any given time can be produced. For this purpose a two-dimensional (latitude/longitude) advection and data-assimilation model has been developed [the Assimilation Model KNMI (AMK)] in which total ozone is advected by a wind field at a single pressure level. The data assimilation is performed by taking weighted averages of advected ozone and ozone-satellite measurements. To our knowledge this is one of the first times in which a data-assimilation technique has been used for total ozone. The model uses wind fields from the European Centre for Medium Range Weather Forecasts (ECMWF) model and total-ozone data measured by the TOVS instruments; i.e. AMK is an off-line model which does not calculate its own wind field. The three-dimensionality of the atmosphere versus the two-dimensionality of total ozone poses however a problem. Total-ozone data do not determine in a unique way the ozone profile. If a threedimensional model is used for the advection, an approach is to assume a vertical ozone distribution, and normalise this with total-ozone observations. As there is a wellestablished relation between the ozone mixing ratio and potential vorticity (Danielsen, 1985), an obvious choice is to take the potential-vorticity profile as an approximation
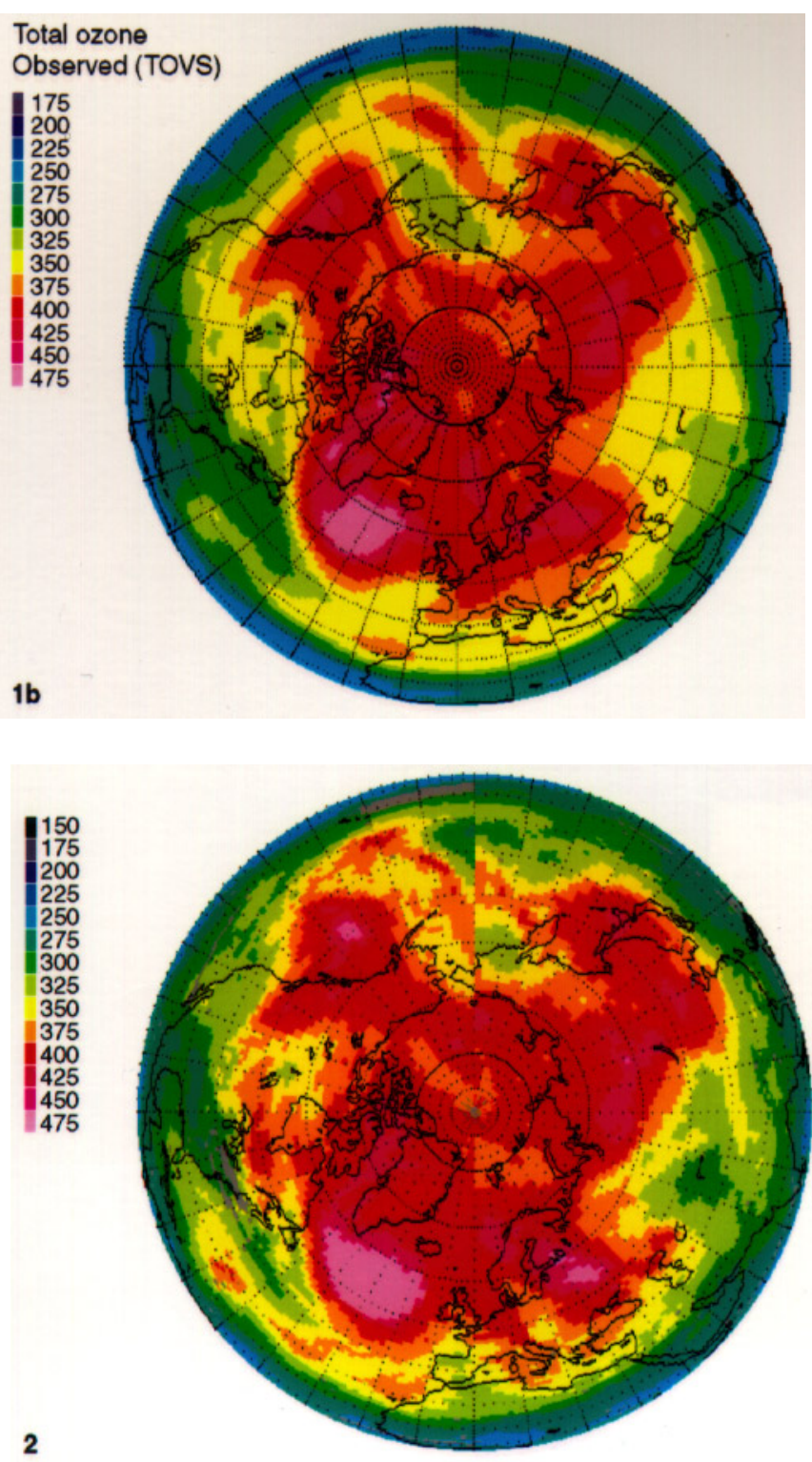

Fig. 2. NASA TOMS total-ozone map (in DU) for 23 April 1992. Spurious gradients are visible at the date line $180^{\circ} \mathrm{E}$ (top of the picture)

for the ozone profile; this was done by Lary et al. (1995). However, in the AMK the problem is solved differently; in this paper it is shown that the changes in the total-ozone field can be described accurately (i.e. within the uncertainty of TOVS) by advecting total ozone using only wind fields at a single pressure level. Moreover, a procedure to determine which level should be used is presented. In Fig. 1b, the ozone field at 23 April 1992 at 1200 UTC resulting from the AMK is shown. Different meteorological features are clearly distinguishable in the ozone distribution, for example an extended tongue of high ozone values between Alaska and Russia (top of the picture), which is not clearly distinguishable in Fig. 1a and displaced in Fig. 2.

In this paper it will be shown that the AMK is able to cope with the incomplete space-time distribution of satellite data, by virtue of data-assimilation techniques. Maps 
without spurious gradients, as shown in Fig. 2 (constructed by plotting adjacent tracks of TOMS data), can then be obtained. A third method of representing satellite data is the use of weighted time- and space-averaging of satellite data. Global maps without gaps in the data-field (see Fig. 1a) and without strong spurious gradients due to different times of observation as shown in Fig. 2, can then also be obtained. However, this kind of interpolated map will not be able to capture the dynamics in the ozone field, and gradients in this field are therefore not described properly. Moreover, the AMK is also suitable for predicting the ozone field a few days ahead.

The data-assimilation technique used in the AMK is chosen for its relative simplicity in order to limit the computation time of the model. Moreover, for the purpose of assimilating only column amounts of ozone from TOVS, a more elaborate data-assimilation technique is not needed, given the relatively high data rate of the TOVS instruments.

\section{Data description}

The wind data are acquired from the Meteorological Archive and Retrieval System (MARS) archives at ECMWF. The 6-h forecast ("first guess") horizontal windfield components at single pressure levels with a resolution of $1^{\circ} \times 1^{\circ}$ are used. First-guess wind fields are used instead of analysed wind fields; experiments showed that firstguess wind fields and analysed wind fields resulted in practically the same global ozone field. Wind fields are available every $6 \mathrm{~h}$ (at 0000, 0600, 1200 and 1800 UTC) and the wind field is assumed to be frozen during each 6-h interval. The TOVS total-ozone data are from the National Oceanic and Atmospheric Administration (NOAA) (Smith et al., 1979). The TOVS instrument on board the NOAA's operational meteorological polar satellites measures the thermal infrared emission of the atmosphere in several channels. One channel coincides with an absorption band of ozone near $9.7 \mu \mathrm{m}$. NOAA National Environmental Satellite, Data, and Information Service (NESDIS) computes the total-ozone content from the measured infrared radiances (Planet et al., 1984). These total-ozone data with a resolution of 80 to $120 \mathrm{~km}$ are also stored in, and available from, the MARS archives. The ozone data of both NOAA-11 and NOAA-12 satellites are used.

\section{Model description}

The AMK is a two-dimensional (latitude/longitude) global model with a uniform horizontal resolution of approximately $100 \times 100 \mathrm{~km}^{2}$ (Levelt and Allaart, 1994). The grid boxes are equally spaced in latitude, but their number at each latitude circle decreases, going from the equator towards the poles, in order to maintain the uniform resolution. It is an off-line model which advects total column ozone with a pre-calculated wind field. Total ozone is assumed to behave as a passive tracer. This approximation applies only if the dynamical timescale (typically $6 \mathrm{~h}$ ) is much smaller than the chemical timescale of ozone. This condition is valid for the upper troposphere and the lower stratosphere, where the chemical lifetime of ozone varies from weeks to months, except under ozone-hole conditions.

The AMK advects and assimilates column amounts of ozone and uses no ozone-profile information. The crucial assumption made is that transport of ozone column amount can to a good approximation be described by the wind field at a well-chosen pressure level. In the upper troposphere and the stratosphere, air, and hence ozone, flows approximately along surfaces of constant potential temperature and constant potential vorticity. In the extratropics, potential-temperature surfaces approximately coincide with isobaric surfaces. Therefore column amount of ozone can be advected along isobaric surfaces. A wind field at a single pressure level is used; which pressure level is optimal is discussed in Sect. 5 .

The core of the AMK is the solution of the linear advection equation, assuming ozone column amount $(\varphi)$ to behave as a passive tracer, and $\mathbf{v}$ to be the wind field:

$\frac{\partial \varphi}{\partial t}+\mathbf{v} \cdot \nabla \varphi=0$.

A huge body of literature exists on the solution of the advection diffusion equation [e.g. Rood (1987) for an extensive review, and references therein]. Here, the firstorder forward-in-time upwind technique is implemented to solve the advection equation, resulting in the following formula for the two-dimensional case:

$$
\begin{aligned}
\varphi_{i, j}^{n+1}= & \varphi_{i, j}^{n}-\Delta t\left\{\min \left(\mathrm{u}_{i, j}, 0\right) \frac{\varphi_{i+1, j}^{n}-\varphi_{i, j}^{n}}{x_{i+1, j}-x_{i, j}}\right. \\
& -\max \left(\mathrm{u}_{i, j}, 0\right) \frac{\varphi_{i, j}^{n}-\varphi_{i-1, j}^{n}}{x_{i, j}-x_{i-1, j}} \\
& -\min \left(\mathrm{v}_{i, j}, 0\right) \frac{\varphi_{i, j+1}^{n}-\varphi_{i, j}^{n}}{y_{i, j+1}-y_{i, j}} \\
& \left.-\max \left(\mathrm{v}_{i, j}, 0\right) \frac{\varphi_{i, j}^{n}-\varphi_{i, j-1}^{n}}{y_{i, j}-y_{i, j-1}}\right\},
\end{aligned}
$$

where $x$ and $y$ are respectively the longitudinal and latitudinal direction, $\mathrm{u}$ and $\mathrm{v}$ are respectively the wind field in the $x$ and the $y$ direction, $\varphi^{n+1}$ and $\varphi^{n}$ is the tracer field before and after the advection step with timestep $\Delta t=t^{n+1}-t^{n}, i$ is the index of the gridbox in longitudinal direction and $j$ is the index for the gridbox in latitudinal direction and $\max \left(\mathrm{u}_{i, j}, 0\right)$ or $\min \left(\mathrm{u}_{i, j}, 0\right)$ means that the maximal or minimal value of $\mathrm{u}_{i, j}$ and 0 should be taken, respectively. The timestep $\Delta t$ for the advection is limited by the Courant-Friedrichs-Lewy (CFL) criterion. Due to the uniform resolution of the grid towards the poles, the timestep can be chosen 50- to 100-times larger than on a $1^{\circ} \times 1^{\circ}$ grid. $\Delta t$ is taken to be 6 min.

\section{Data assimilation}

The data-assimilation technique used in the model is the so-called single-correction method, introduced by 
Bergthórsson and Döös (1955), which is the forerunner of the method of successive corrections (Daley, 1991). In the implementation of the method used here, an analysed ozone field at time $t+\Delta t$ is obtained by taking a weighted average between the background field at $t+\Delta t$ and observed ozone data obtained between $t$ and $t+\Delta t$. For practical reasons the assimilation timestep is the same as the advection timestep in the AMK ( $\Delta t=6 \mathrm{~min})$.

Starting from an ozone field at $t$, a first-guess ozone field at $t+\Delta t$ is calculated with the advection procedure already mentioned. This first-guess field is used as a background field in the data-assimilation procedure. The background ozone field at $t+\Delta t\left(\varphi^{\mathrm{b}}\right)$ is weighted with observed ozone data $\left(\varphi^{\circ}\right)$ obtained between $t$ and $t+\Delta t$, using only a single correction step. An analysed ozone map at $t+\Delta t$ is then obtained.

The analysed ozone value $\varphi_{i}^{\mathrm{a}}$ is defined by:

$\varphi_{i}^{\mathrm{a}}=\varphi_{i}^{\mathrm{b}}+W_{i k}\left(\varphi_{k}^{\mathrm{o}}-\varphi_{k}^{\mathrm{b}}\right)$.

Here $\varphi_{i}^{\mathrm{b}}$ and $\varphi_{k}^{\mathrm{b}}$ are background ozone at the gridpoint $i$ and the observation point $k$, respectively, and $\varphi_{k}^{\mathrm{o}}$ is the observed ozone at observation point $k, W_{i k}$ is a weighting coefficient and $\left(\varphi_{k}^{\mathrm{o}}-\varphi_{k}^{\mathrm{b}}\right)$ is the observation increment. If $K$ observations are available, then Eq. 3 becomes:

$\varphi_{i}^{\mathrm{a}}=\varphi_{i}^{\mathrm{b}}+\sum_{k=1}^{K} W_{i k}\left(\varphi_{k}^{\mathrm{o}}-\varphi_{k}^{\mathrm{b}}\right)$,

wherein $W_{i k}$ are the weighting coefficients which are a priori specified:

$W_{i k}=\frac{\sigma_{\mathrm{b}}^{2} \omega\left(r_{i k}\right) \rho}{\sigma_{\mathrm{o}}^{2}+\sum_{k=1}^{K} \sigma_{\mathrm{b}}^{2} \omega\left(r_{i k}\right) \rho}$,

where $\sigma_{\mathrm{o}}^{2}$ is the observation-error variance, $\sigma_{\mathrm{b}}^{2}$ is the background-error variance, $r_{i k}$ is the distance between analysis point $i$ and observation point $k$ and $\rho$ is a correction function. $\omega\left(r_{i k}\right)$ contains information about the influence of an observation at point $k$ on the ozone value of the gridbox at point $i$ that is being analysed. $\omega\left(r_{i k}\right)$ is assumed to be dependent only on the distance between $i$ and $k$ and has the following properties:

$\omega\left(r_{i k}\right)=1 \quad$ when $r_{i k}=0 \quad$ and $\quad \omega\left(r_{i k}\right) \rightarrow 0 \quad$ if $\left|r_{i k}\right| \rightarrow \infty$.

The weight $\omega\left(r_{i k}\right)$ has been determined by several methods. Cressman (1959) and Sasaki (1960) adopted an $r$-dependent function for $\omega\left(r_{i k}\right)$, whereas Bergthórsson and Döös (1955) derived the weight $\omega\left(r_{i k}\right)$ statistically from data. In this paper the weights are estimated from the calculation of an error covariance matrix with elements $\overline{\left(\varphi_{\mathrm{o}}-\varphi_{\mathrm{b}}\right)_{k}\left(\varphi_{\mathrm{o}}-\varphi_{\mathrm{b}}\right)_{l}}$, which corresponds to the mean of the product of the differences $\left(\varphi_{\mathrm{o}}-\varphi_{\mathrm{b}}\right)$. It is assumed that the observation error is spatially uncorrelated as well as uncorrelated with the background error. This results in:

$$
\begin{aligned}
\overline{\varphi_{\mathrm{o}}} & \left.-\varphi_{\mathrm{b}}\right)_{k}\left(\varphi_{\mathrm{o}}-\varphi_{\mathrm{b}}\right)_{l} \\
& =\overline{\left\{\left(\varphi_{\mathrm{o}}-\varphi_{t}\right)-\left(\varphi_{\mathrm{b}}-\varphi_{t}\right)\right\}_{k}\left\{\left(\varphi_{\mathrm{o}}-\varphi_{t}\right)-\left(\varphi_{\mathrm{b}}-\varphi_{t}\right)\right\}_{l}} \\
& =\left\{\delta_{k}^{\mathrm{o}} \delta_{l}^{\mathrm{o}}-\delta_{k}^{\mathrm{o}} \delta_{l}^{\mathrm{b}}-\delta_{k}^{\mathrm{b}} \delta_{l}^{\mathrm{o}}+\delta_{k}^{\mathrm{b}} \delta_{l}^{\mathrm{b}}\right\} \\
& =\sigma_{\mathrm{b}}^{2} \mu\left(r_{k l}\right) \quad \text { for } r_{k l} \neq 0
\end{aligned}
$$

and

$$
=\sigma_{\mathrm{o}}^{2}+\sigma_{\mathrm{b}}^{2} \text { for } r_{k l}=0,
$$

where $\varphi_{t}$ is the true ozone value, $\delta^{\mathrm{o}}$ and $\delta^{\mathrm{b}}$ are the error in the observation and the model, respectively, and $\mu\left(r_{k l}\right)$ is the correlation between background ozone error at the observation points $k$ and $l$. For the calculation of the elements $\left(\varphi_{\mathrm{o}}-\varphi_{\mathrm{b}}\right)$ in the error covariance matrix the advected value at the gridpoint closest to the observation is taken. Furthermore, the covariance is assumed to be only dependent on the distance between the observations, and is thus not a function of their absolute positions or their relative orientation, which means that the correlation $\mu$ is only $r$-dependent. Thus, calculating the error covariance matrix gives information about the correlation between the error in advected ozone at point $k$ and the error in advected ozone at point $l$, and as such provides a weight $\omega\left(r_{i k}\right)$ for the difference $\left(\varphi_{\mathrm{o}}-\varphi_{\mathrm{b}}\right)_{k}$ at observation point $k$ to be applied at gridpoint $i$ (see Eq. 4). In this paper the correlation $\mu(r)$ is used as the weight $\omega\left(r_{i k}\right)$.

The error covariance matrix is calculated by summing over contributions per distance interval $r_{k l}$, where $r_{k l}$ is the distance between observation points $k$ and $l$. In the absence of systematic differences between $\varphi_{\mathrm{o}}$ and $\varphi_{\mathrm{b}}$, the error covariance should decrease to zero at large distance $\left(r_{k l} \rightarrow \infty\right)$. This reflects the fact that observations which lie far apart from the gridbox being analysed have little influence.

In Fig. 3 the error covariance matrix calculated per distance interval of $100 \mathrm{~km}$ is shown. At $k=l$ the error variance $\sigma_{\mathrm{o}}^{2}+\sigma_{\mathrm{b}}^{2}$ is 250 and $350 \mathrm{DU}^{2}$ for NOAA-11 and NOAA-12 TOVS data, respectively. For determining the coefficients $\omega\left(r_{i k}\right)$ from the covariance matrix we assume that the observation-error variance is equal to the background-error variance (i.e. $\sigma_{\mathrm{o}}^{2}=\sigma_{\mathrm{b}}^{2}$ ), which is a reasonable zero-order approximation. The observation-error variance, as well as the background-error variance, is then 125-175 $\mathrm{DU}^{2}$, resulting in an observation error of 11-13 DU. The error in TOVS observations on the TIROS-N series of satellites is in the order of 15-20 DU

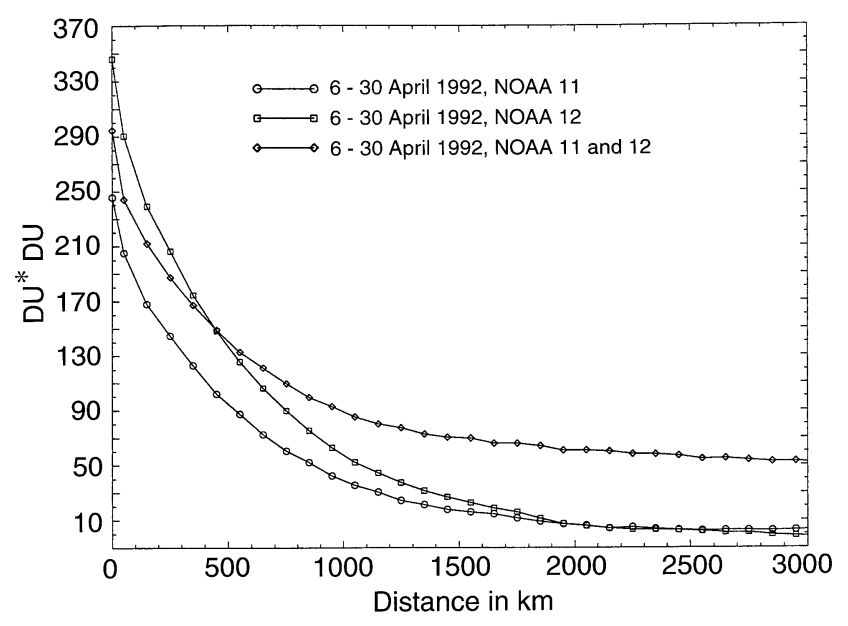

Fig. 3. The error covariance $\left(\varphi_{\mathrm{o}}-\varphi_{\mathrm{b}}\right)_{k}\left(\varphi_{\mathrm{o}}-\varphi_{\mathrm{b}}\right)_{l}$ averaged for 6 to 30 April 1992 
(Planet et al., 1984). The error correlation $\mu(r)$, and thus the weighting coefficients $\omega\left(r_{i k}\right)$, was then obtained after dividing the error covariance $\sigma_{\mathrm{b}}^{2} \mu(r)$ (for $r \neq 0$ ) by the error variance $\sigma_{\mathrm{b}}^{2}$. Equation 4 can then be written as:

$\varphi_{i}^{\mathrm{a}}=\varphi_{i}^{\mathrm{b}}+\sum_{k=1}^{K} \frac{\mu\left(r=r_{i k}\right) \rho}{1+\sum_{k=1}^{K} \mu\left(r=r_{i k}\right) \rho}\left(\varphi_{k}^{\mathrm{o}}-\varphi_{k}^{\mathrm{b}}\right)$.

The calculation of the error covariance was performed for the entire month April 1992 and the error covariance in Fig. 3 was obtained by averaging over the results from 6 April to 30 April 1992, allowing for a spin-up time of the model of 5 days. The $50-\mathrm{km}$ point in the covariance plot is the average of the contributions obtained in the interval from 1 to $99 \mathrm{~km}$, the $150-\mathrm{km}$ point in the interval from 100 to $199 \mathrm{~km}$, etc. As expected, the covariance is a decreasing function of the distance between observations, becoming negligible after $1500 \mathrm{~km}$. This is consistent with the spatial extent of synoptic weather systems, which are reflected in the ozone field. However, $\mu\left(r_{k l}\right)$ is larger than 1 for $r_{k l}<400 \mathrm{~km}$. This means that the assumption of spatially uncorrelated observation errors can not be true for this interval, given that $\sigma_{\mathrm{o}}^{2}=\sigma_{\mathrm{b}}^{2}$. This problem can be solved by taking into account a correction factor $\rho$ (Bergthórsson and Döös, 1955). This function can for example be chosen to be the ratio of one over the amount of observations redundant with observation $k$. We have chosen $\rho$ to be equal to 0.5 .

A radius of $150 \mathrm{~km}$ is taken for the circle of influence of an observation. This means that for the grid used in the AMK $(100 \times 100 \mathrm{~km})$, weighting coefficients are needed for 100 and $140 \mathrm{~km}$ approximately. These distances are based on a simplified representation of the grid as shown in Fig. 4. The coefficients were determined by interpolation of the $50-$ and $150-\mathrm{km}$ values from the error covariance calculated for NOAA-11 data in Fig. 3. With these improved coefficients, the procedure, starting with the calculation of the error covariance matrix for the entire month April 1992, was repeated until the weights no longer changed significantly (which was already after the second iteration). The $\omega\left(r_{i k}\right) \rho=\mu(r) \rho$ thus obtained are 1 , 0.76 and 0.70 , for distances $r_{k l}$ equal to 0,100 and $140 \mathrm{~km}$,

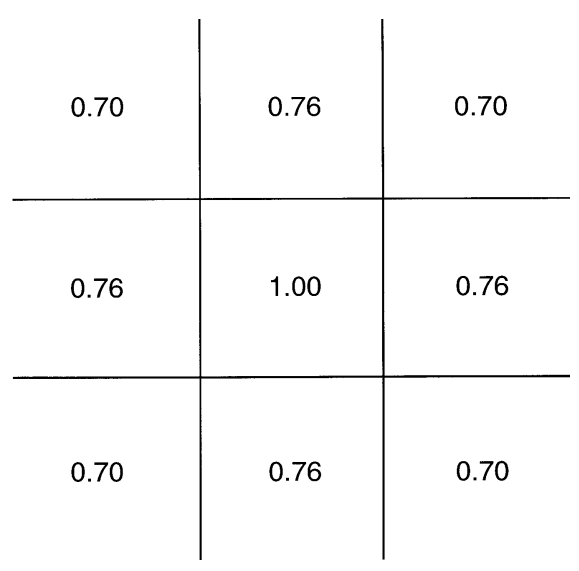

Fig. 4. In the grid boxes the coefficients $\mu(r) \rho$ are shown respectively, as is shown in Fig. 4. Experiments with slightly different weighting coefficients indicate that the model performance is relatively insensitive to the exact choice of weighting coefficients. Coefficients obtained for NOAA-11 or NOAA-12 data are practically identical.

Assimilating both NOAA-11 and/or NOAA-12 TOVS ozone data resulted in different covariance matrices. The difference when using both NOAA-11 and NOAA-12 data is not yet understood. However, an explanation could be a systematic bias in the order of $6 \mathrm{DU}$, between NOAA-11 and NOAA-12 total ozone values. If there is a systematic bias between the NOAA-11 and -12 observations, the advected ozone can not be consistent with both types of satellite data. The resulting bias between advected data and observed data is reflected in the error covariance, especially for $r_{k l} \rightarrow \infty$.

\section{The choice of the wind field}

The optimal wind field is determined empirically as the wind field which gives the smallest rms difference between advected-total-ozone and observed-total-ozone data in the timeframe of the advection step:

$\varepsilon=\sqrt{1 / K \sum_{k=1}^{K}\left(\varphi_{k}^{\mathrm{o}}-\varphi_{k}^{\mathrm{b}}\right)_{k}^{2}}$,

where $K=$ number of observations, $\varphi_{k}^{o}=$ observed total ozone, $\varphi_{k}^{\mathrm{b}}=$ advected total ozone, $\varepsilon=$ root mean square difference and $k=$ observation.

Wind-field levels used are 50,70,100, 200, 250, 300 and $500 \mathrm{hPa}$. As a test case April 1992 is chosen, because of the high variability of the ozone-field as well as the absence of fast (ozone-hole) chemistry. The initial ozone field is an analysed ozone field, obtained by running the AMK for about 1 year prior to April 1992. In principle 7 days would have been enough to obtain an accurate analysed ozone field as initial field, starting from an uniform ozone field of 300 DU. Experiments with 7-day runs showed that the obtained analysed ozone field, compared with an ozone field constructed by continuous data assimilation, revealed only differences between these ozone fields below the $1 \%$ level. This means that the difference in rms error $\varepsilon$ obtained for the two analysed ozone fields diminishes in $30 \mathrm{~h}$ to half of its original value. As the AMK is continuously used, the initial field was obtained by running the model for about 1 year.

To test the behaviour of the model, gaps of 4 days in the ozone data have been introduced artificially. In this 4-day period the ozone field is only advected, i.e. no observations are used. These ozone-data-deficient periods are followed by a period of 5 days wherein data assimilation uses all available TOVS ozone data in order to recover a realistic total-ozone distribution. This procedure is repeated three times. The scheme is shown in Table 1. In order to investigate whether different wind fields are needed for transporting total ozone in dynamically differently behaving parts of the atmosphere, $\varepsilon$ is also calculated separately for the northern hemisphere outside the equatorial region $\left(30^{\circ}-90^{\circ} \mathrm{N}\right)$, the equatorial region $\left(30^{\circ} \mathrm{N}-\right.$ $30^{\circ} \mathrm{S}$ ) and the southern hemisphere outside the equatorial 
Table 1. Description of data used to test which wind-field level is the optimal choice to run the AMK. As a test case, TOVS data of April 1992 are taken $(\mathrm{adv}=$ advection, ass $=$ assimilation $)$

\begin{tabular}{lcllll}
\hline DATA or GAP & $\begin{array}{l}\text { Day } \\
\text { in April }\end{array}$ & $\begin{array}{l}\text { Hour } \\
\text { (UTC) }\end{array}$ & $\begin{array}{l}\text { Day } \\
\text { in April }\end{array}$ & $\begin{array}{l}\text { Hour } \\
\text { (UTC) }\end{array}$ \\
\hline DATA (adv + ass) & 1 & 0000 & - & 3 & 2400 \\
GAP (adv) & 4 & 0000 & - & 7 & 2400 \\
DATA (adv + ass) & 8 & 0000 & - & 12 & 2400 \\
GAP (adv) & 13 & 0000 & - & 16 & 2400 \\
DATA (adv + ass) & 17 & 0000 & - & 21 & 2400 \\
GAP (adv) & 22 & 0000 & - & 25 & 2400 \\
DATA (adv + ass) & 26 & 0000 & - & 30 & 2400 \\
\hline
\end{tabular}

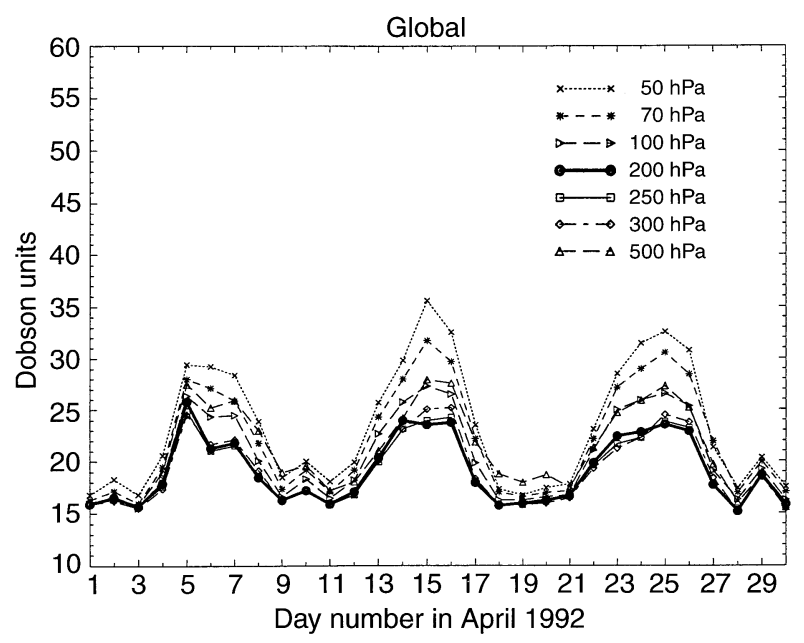

Fig. 5. The rms-difference $\varepsilon$ of advected TOVS data compared to raw TOVS data (see Eq. 6) for the total globe, calculated for a wind field at the pressure levels 50, 70, 100, 200, 250, 300 and $500 \mathrm{hPa}$

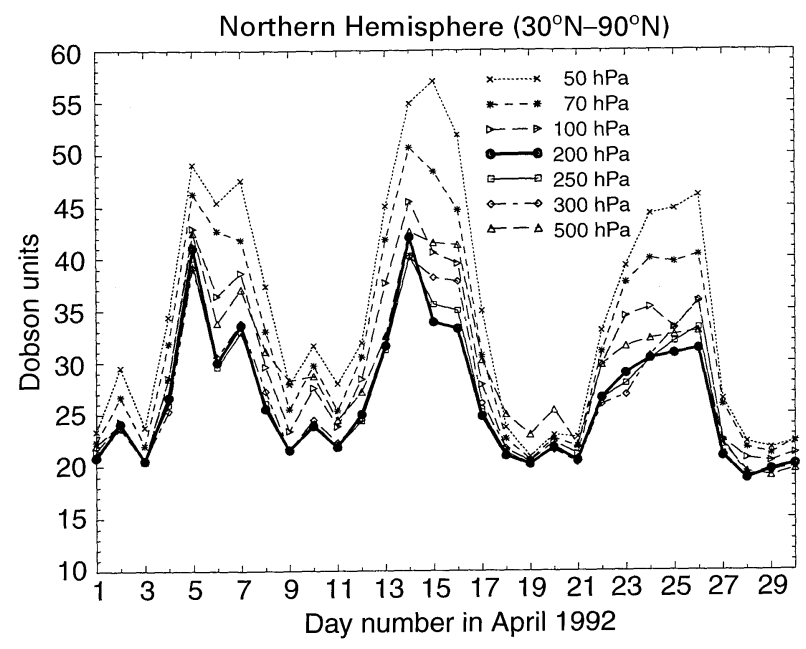

Fig. 6. As in Fig. 5 but only for the $\mathrm{NH}$ region $\left(30^{\circ}-90^{\circ} \mathrm{N}\right)$

region $\left(30^{\circ}-90^{\circ} \mathrm{S}\right)$, which are noted as the $\mathrm{NH}, \mathrm{EQ}$ and $\mathrm{SH}$ region, respectively.

In Figs. 5-8, values of $\varepsilon$ for all wind fields, for the $\mathrm{NH}$, EQ and SH regions, and averaged over the whole globe, are presented. An oscillating structure in $\varepsilon$ is easily

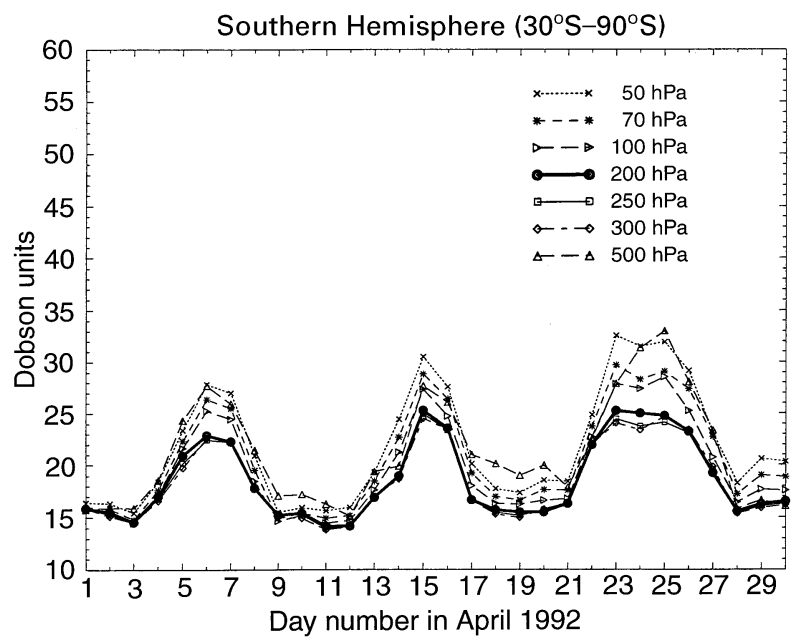

Fig. 7. As in Fig. 5 but only for the $\mathrm{SH}$ region $\left(30^{\circ}-90^{\circ} \mathrm{S}\right)$

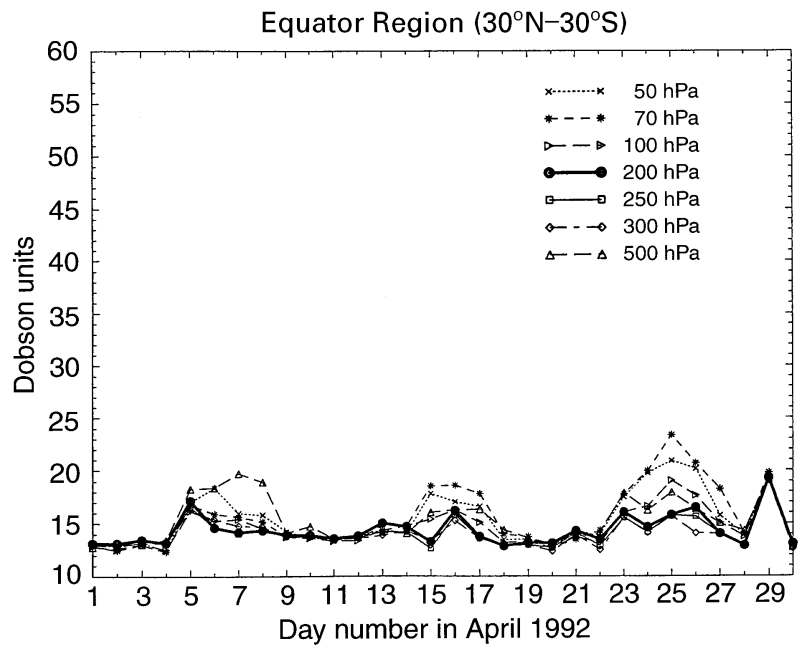

Fig. 8. As in Fig. 5 but only for the EQ region $\left(30^{\circ} \mathrm{N}-30^{\circ} \mathrm{S}\right)$

denoted, which is caused by the artificially produced data gaps. During periods without data assimilation, $\varepsilon$ increases sharply until it stabilises after 2 days $(4-7,13-16$ and 22-25 April). As soon as new satellite data are introduced by data assimilation, $\varepsilon$ decreases and also stabilises after 2 days (8-12,17-21 and 26-30 April). Thus the global ozone map is recovered after 3 days of advecting and assimilating satellite data. The increase in $\varepsilon$ is most extreme in the NH region (between 20 and $58 \mathrm{DU}$ ), and much smaller on the SH region (between 15 and 33 DU) and at the EQ region (between 13 and 25 DU). Between the different latitude bands in the NH, 30-50 N, 50-70 N and $70-90 \mathrm{~N}$, no significant difference in $\varepsilon$ is found (not shown). The high sensitivity upon the right choice of wind field in the NH region is caused by the greater spatial and temporal variability in the ozone field during winter and spring in the $\mathrm{NH}$ region than in the EQ region and, to a lesser extent, in the SH region. This will result in a higher sensitivity upon the choice of wind field for the $\mathrm{NH}$ region compared to the EQ and $\mathrm{SH}$ regions.

The 200- or $250-\mathrm{hPa}$ wind-field levels are clearly the best pressure-level wind fields for transporting column 
amount of ozone, followed by the $300-\mathrm{hPa}$ wind-field level. This is true for the global, NH, SH and EQ calculations (see Figs. 5-8). This confirms that the maximum variability is indeed around and above tropopause level, which is between 200 and $300 \mathrm{hPa}$ in the NH at midlatitudes.

Similar results are also found by Riishøjgaard and Lary (1994). They studied the correlation between the forecast error for total ozone and the forecast error for geopotential height at $50,200,500$ and $850 \mathrm{hPa}$ in the northernhemisphere extratropics. The geopotential height error near tropopause level $(200 \mathrm{hPa})$ showed the strongest correlation.

\section{Discussion and conclusions}

The two-dimensional model, AMK, for advection and assimilation of total-ozone satellite data using a wind field at a single pressure level, has been presented. The model is powerful for assimilating satellite data, even, for example, for satellites with a narrow swath width, such as GOME, or satellite data with gaps due e.g. to retrieval problems, as is shown in this study using TOVS data. By alternating periods of 4 days of only advection and no data assimilation with periods of 5 days of advection and assimilation, it can be concluded that the $200-\mathrm{hPa}$ wind-field level is a good choice of wind field to advect total-ozone-column data. Using a different approach the same wind-field level was also found by Riishøjgaard and Lary (1994). Consideration of atmospheric dynamics permits a first understanding why this wind field should be used for advecting total ozone. Successive satellite measurements of total ozone detect changes in the ozone column amount, which is the resultant of ozone transport by different winds at different levels. If the ozone concentration is uniform over the globe, no changes in column amounts would be visible. Since high-pressure regions correspond to low ozone values and low-pressure regions to high ozone values (Dobson, 1968), meteorological features appear to be clearly distinguishable in the total-ozone field. These highand low-pressure regions are accompanied by substantial fluctuations in the tropopause height. Moreover there is a strong vertical gradient in the ozone mixing ratio just above the tropopause. The synoptic scale changes in total ozone are thus expected to be caused by changes in the ozone distribution around the tropopause level. It is therefore reasonable to assume that wind fields at pressure levels around the tropopause are representative wind fields to describe the transport of column amount of ozone. As was shown, the most simple choice of transport by a wind field at a single pressure level already gives a reasonable description of the transport of the column amounts of ozone. Vertical velocities near the tropopause will also lead to changes in total ozone. In this study the effects of vertical motions have been neglected. In the atmosphere both mechanisms are expected to contribute to the variability of total ozone. The small rms differences, $\varepsilon$, found in this study suggest however, that changes in column amounts of ozone due to horizontal motions are more important than those due to vertical motions.
The model is also used for validating the GOME instrument measurements (Piters et al., 1996). Validation of satellite data by ground-based measurements is important, especially for long-term trend detection, ozone climatology and intercomparison of data measured by different satellites. However, ground-based measurements taken at different times and different geographical locations from the satellite measurements are less suited for direct comparison. Also, satellite measurements usually represent averages over a large area, whereas conventional measurements represent local values, which makes the two not directly comparable. The AMK, which retains the dynamical information on ozone, makes it possible to use also these non-collocated measurements for validation. Moreover, data assimilation offers the possibility to identify ground stations which deliver controversial data by comparison with observations of a satellite instrument.

This model is a first attempt to advect and assimilate total-ozone data and can be improved in several ways. A time-interpolated wind field between the 3-, 6- and 9-h forecasts can be used, instead of taking a fixed wind field during a 6-h period. Moreover, other wind fields could be taken into account. A combination of wind fields at different heights would be an obvious choice. This would be a first step towards a three-dimensional approach. For ozone-profile satellite data a three-dimensional approach, as was already shown by Riishøjgaard (1995) and Swinbank and O' Neill (1994), is needed. However, it should be mentioned that the two-dimensional approach in the AMK is very useful, because most satellite instruments available produce high-quality measurements of column amounts of ozone and considerably less profile information of ozone. The data-assimilation technique used in our model is a first step and will be improved by extending the radius of influence of the observations (currently $150 \mathrm{~km}$ ). More elaborate data-assimilation methods, such as Optimal Interpolation or four-dimensional variational techniques (Daley, 1991), will be needed when other tracers are also taken into account, or when one wants to extract dynamical information from the ozone field. Some of these different aspects will be considered in the near future.

Acknowledgements. The research of P. F. L. has been funded by the Beleidscommissie Remote Sensing (BCRS). We thank NOAA NESDIS, NASA and ECMWF for making available the TOVS data, TOMS data and MARS archive data, respectively. We thank Ad Stoffelen and Elías Hólm for many interesting discussions and contributions, especially on the subjects of data assimilation and advection. We thank the referees for their valuable comments.

Topical Editor F. Vial thanks R. Swinbank and L. P. Riishøjgaard for their help in evaluating this paper.

\section{References}

Allaart, M. A. F., H. Kelder, and L. C. Heijboer, On the relation between ozone and potential vorticity, Geophys. Res. Lett., 20, 811, 1993.

Bergthórsson, P., and B. R. Döös, Numerical weather map analysis, Tellus, 7, 329, 1955.

Cressman, G., An operational objective analysis system, Mon. Weather Rev., 87, 367, 1959.

Daley, R., Atmospheric Data Analysis, Cambridge University Press, Canada, 1991. 
Danielsen, E. F., Ozone transport, in Ozone in the Free Atmosphere, eds. R. C. Whitten and S. S. Prasad, Van Nostrand Reinhold, New York, pp. 123-159, 1985.

Dobson, G. M. B., Forty years' research on atmospheric ozone at Oxford: a history, Appl. Opt., 7, 387, 1968.

Dobson, G. M. B., D. N. Harrison, and J. Lawrence, Measurement of the amount of ozone in the Earth's atmosphere and its relation to other physical conditions, Proc. Roy. Soc., A122, 456, 1928.

ESA Document, Mission Objectives, User and System Requirements for an Ozone Monitoring Instrument on METOP, in press, 1996

Hahne, A., J. Lefebvre, J. Callies, and R. Zobl, GOME: a new instrument for ERS-2, ESA Bulletin, 73, 22, 1993.

Heath, D. F., A. J. Krueger, H. A. Roeder, and B. D. Henderson, The solar backscatter ultraviolet and total ozone mapping spectrometer (SBUV/TOMS) for NIMBUS G, Opt. Eng., 14, 323, 1975.

Heijboer, L. C., H. Kelder, M. J. M. Saraber, and P. F. J. van Velthoven, An analytical model describing the basic structure and development of mature extratropical cyclones, accepted for publication in Mon. Weather Rev., 1996.

Lary, D. J., M. P. Chipperfield, J. A. Pyle, W. A. Norton, and L. P. Riishøjgaard, Three-dimensional tracer initialization and general diagnostics using equivalent PV latitude-potential-temperature coordinates, Q. J. R. Meteorol. Soc., 121, 187, 1995.

Levelt, P. F., and M. A. F. Allaart, Two-dimensional advection model for interpolation of ozone satellite data, Proc. of SPIE Atmos. Sensing and Modelling, 29-30 Sept. 1994, Rome, Italy., 2311, 217, 1994.
Piters, A. J. M., P. F. Levelt, M. A. F. Allaart, and H. M. Kelder, Validation of GOME total ozone column with the assimilation model KNMI, GOME Geophysical Validation Campaign, Final Results, Workshop Proceedings, held by ESA-ESRIN in Frascati 24-26 January 1996.

Planet, W. G., D. S. Crosby, J. H. Lienisch, and M. L. Hill, Determination of Total Ozone Amount from TIROS Radiance Measurements, J. Clim. Appl. Meteorol., 23, 308, 1984.

Riishøjgaard, L. P., On four-dimensional variational assimilation of ozone data in weather prediction models, accepted for publication in Quart. J. Roy. Meteor. Soc., 1995.

Riishøjgaard, L. P., and D. J. Lary, Short-range simulations of extratropical total ozone with APERGE/-IFS, Proc. of ECMWF Workshop on the stratosphere and numerical weather prediction, ECMWF, 1994

Rood, R. B., Numerical advection algorithms and their role in atmospheric transport and chemistry models, Rev. Geophys., $\mathbf{2 5}$, $71,1987$.

Sasaki, Y, An objective analysis for determining initial conditions for the primitive equations, Tech. Rep. (Ref. 60-16T) (College Station: Texas A\&M University), 1960.

Smith, W. L., H. M. Woolf, C. M. Hayden, D. Q. Wark, and L. M. McMillen, The TIROS-N operational vertical sounder, Bull. Am. Meteorol. Soc., 60, 1177, 1979.

Stolarski, R. S., P. Bloomfield, and R. D. McPeters, Total ozone trends deduced from Nimbus 7 TOMS data, Geophys. Res. Lett., 18, 1015, 1991.

Swinbank, R., and A. O'Neill, A stratosphere-troposphere data assimilation system, Mon. Weather. Rev., 122, 686, 1994. 